\title{
Nomenclature of Martensites in $\beta$-Phase Alloys
}

\author{
L. Delaey*(1) and M. Chandrasekaran** \\ *Dep. ING. Quimica y Metalurgia, Univ.de Barcelona \\ ** AMT-Advanced Materials Technology, B-3540 Herk-de-Stad, Belgium
}

\begin{abstract}
The paper discuss the nomenclature of martensites in the $\beta$-phase alloys and proposes to continue to use the current nomenclature with emphasis on the correct interpretations in terms of stacking sequence of the basal planes and the true symmetry of the martensite structure.
\end{abstract}

In their paper "New description of Long Period Stacking Order Structures of Martensites in $\beta$-Phase Alloys" Otsuka et al [1] propose a new nomenclature to describe the long period stacking order in martensitic $\beta$-phase alloys. The new scheme should, according to the authors, offer a number of advantages. The authors are right in renewing the earlier observation $[2,3$ and 4$]$ that the structural representation in the present nomenclature and description does not reflect the true symmetry of the structures. However, caution should be excercised in abandoning the existing nomenclature for this reason alone. Instead, both the advantages and disadvantages of the different nomenclatures should be carefully weighed before choosing one or the other. Independent of the nomenclature being followed the space group corresponding to a structure should always be specified. The object of this note is to compare the relative merits and drawbacks of the existing nomenclature as well as the new nomenclature proposed by Otsuka et al [1]. The present paper is based on an earlier published paper [5]

The main drawback in the structural representation of the nomenclature in present use is, that it does not reflect the true symmetry of the martensite structure. The fact that in spite of this drawback, it has found continued usage is due to its overriding merits, viz. the variety of information that it conveys. This is the result of its gradual evolution after several reviews and updates $[6,3 \& 4]$ to accommodate new findings. As detailed in one of the earlier reviews (see table 3 in [4]), the structural representation finds its origin in three basic factors which determine the exact crystal structure of the different martensitic phases in the $\mathrm{Cu}-, \mathrm{Ag}-$, Au- and Ni-based $\beta$-phase alloys. These factors, de-picted schematically in figure 1 of [3], are: the stacking sequence of the close packed planes (CPL's), the long range order in martensite as inherited from the parent $\beta$-phase ordering, and deviations from the regular hexagon arrangement of the atoms in the basal planes of the martensite (the deviations are due to atom size differences and type and degree of order $[3,4]$ ). Before we go into the details of this structural representation, it must be emphasized that it constitutes only a part of the nomenclature. Clearly, the complexity and number of martensite phases which occur in the $\beta$-phase alloys, have necessitated the use of a nomenclature from which all parameters relevant to the martensite transformation can be retrieved. The various elements of this nomenclature are given in table 1 and a specific example of the nomenclature for a martensite along with its significance is shown in fig. 1. Those will be presently elaborated.

(1) On leave of absence from Dept. MTM, Kuleuven, B-3001 Leuven, Belgium 
A phase should firstly be indicated by a phase symbol and by the space group to which the crystal structure belongs. However, neither the phase symbol nor the space group reveal the exact stacking sequence of the close packed planes, which thus has to be specified explicitly. This can be done either in the form of the Ramsdel notation or the Zhdanov symbol, or by describing the full stacking sequence. It has always been a matter of convention and convenience to consider the structure of martensite in the $\beta$ phase alloys as close packed with different stacking sequences. Three types of martensites occur which are not only distinguished by the stacking sequence but also by the micro-structural details within the martensite plate and thus by the inhomogeneous shear associated with the martensite formation. These three types are $[4,6]$ the $\alpha^{\prime}-, \beta^{\prime}$ - and $\gamma^{\prime}$ - martensites, respectively. When the long range order inherited from the $\beta$-phase upon transformation is disregarded, the stacking sequence of the CPLs and the inhomogeneous shear within a plate of each of these types of martensites are as follows:

- the $\alpha^{\prime}$-type with an $\mathrm{ABC}$...- stacking sequence and where the inhomogeneous shear occurs by twinning,

- the $\beta$ '-type with a stacking sequence $\mathrm{ABCBCACAB} \ldots$ and where the inhomogeneous shear occurs by irregularly or regularly distributed stacking disorder, and

- the $\gamma^{\prime}$-type martensite which is characterized by an $\mathrm{AB} \ldots$ or $\mathrm{ABAC} \ldots$ stacking sequence and where the inhomo-geneous shear occurs by twinning.

Each of these three types of martensites, induced thermally and spontaneously on cooling, occur in a typical composition range. Moreover, each type of martensite has a distinct orientation for its habit plane and a distinct orientation relationship with the $\beta$-phase matrix. A common feature in the micro-structure of these martensites, however, is the mutual martensite plate arrangements in forming the so-called selfaccommodating groups of plates. Each type of martensite has its own typical crystallographic relationship within such a group $[4,7,8]$. Upon deforming such a microstructure, there is interconversion of plates which is characteristic for each martensite type till the most favourable plate variant/s prevail corresponding to the direction and level of stress $[7,8]$. The three types of martensite can also be stress induced from the $\beta$-phase or upon deforming an existing martensite type. The same phase symbols are used to depict these martensites as well. The phases occur in distinct stress-temperature ranges. However, in stress induced martensites the details within a plate variant are not necessarily the same as in thermal spontaneously induced martensites. We recommend, therefore, that extra information is provided, so that the reader can distinguish such cases and knows what is being dealt with. Use of the phase symbols $\alpha^{\prime}-, \beta^{\prime}$ - and $\gamma^{\prime}$ - for the stress-induced martensites, immediately informs one about the type of stress-strain response for each type of martensite as well.

The next point of discussion is the long range order that is inherited from the matrix $\beta$-phase. In conformity with earlier proposals $[4,6]$, the subscripts 1,2 , and 3 are related respectively, to $\mathrm{a} \mathrm{DO}_{3}, \mathrm{~B} 2$ or $\mathrm{L} 2_{1}$ (=Heusler) type of superlattice of the parent phase. With continued use of these subscripts as a standard notation for designating the type of long range order, there is no need either to add the respective Structure Reports symbols $\mathrm{DO}_{3}, \mathrm{~B} 2$ or $\mathrm{L} 2{ }_{1}$ separately between brackets or to change the space group symbol $\mathrm{P} 2 / \mathrm{m}$ into $\mathrm{B} 2 / \mathrm{m}$.

The discussion on the long range order leads us back to the stacking sequence representation, on which a conclusion has not yet been expressed. The type of long range order influences the stacking sequence in two ways. In a martensite derived from a $\mathrm{DO}_{3}$ - or an $\mathrm{L} 2{ }_{1}$-phase, six different CPL's have to be used in order to take into account the ordering in the basal plane of the martensite (figure 6 of [3]). So, the total number of close packed planes in one period must be doubled in these cases. The long range order in martensite causes deviations from the regular hexagon arrangement of the atoms in the basal plane of the martensite. A pictorial representation of the basal plane with a regular hexagon for equal sized atoms and the distorted hexagons for two stoichiometric ordered compositions (50/50 and 75/25 at\%) and for specific sizes of the atom is given in figure 5 of ref [4]. The extent of this 'distortion' depends not only on the type of order but also on the degree of long range order. This latter dependence is of outmost importance. Without going into details, one can show that, depending on the quenching rate or quench 
procedures, various degrees of order may be observed. Consequently, the lattice parameters depend not only on alloy composition but also on the quenching rate. It has been proved that after quenching, changes occur in this distortion even at room temperature [10]. It is common knowledge among those studying the fine, but technologically important details of the state of order, that small changes in lattice distortions originating from changes in the degree of order usually have a large effect on the overall characteristics of the shape memory effect. This is thus a characteristic parameter of the martensite structure that should be easily revealed. As shown below, this information can be contained in an 'appropriate' addition to the stacking sequence symbol.

Following the above discussion, the real structure of the martensite phases, when long range ordering is taken into account is to be considered as a derivative of an 'ideal' structure. This 'ideal' structure is described by an ortho-rhombic unit cell - which does not reflect the actual symmetry. Further, the order induced deviations make the c-axes of the unit cell to be inclined in the case of the $\alpha^{4}$-type and $\beta^{\prime}$-type martensite. This angle, which is very easily measured in electron diffraction patterns (unlike exact lattice parameters that are difficult to obtain), should be reported while characterizing the full structure. The corresponding $\mathrm{c}^{*}$-axis in the reciprocal space is by definition always perpendicular to the basal planes. We emphasize that ordering also introduces distortions of the 'ideal' lattice parameters in ordered $\gamma$ '-type martensite. But in $\gamma^{\prime}$-type martensites, the deviation from the ideal structure does not result in an inclination of the c-axis. In order to distinguish martensites with a 'distorted' structure from the orthorhombic normal $(\mathrm{N})$ ones, the term modified $(\mathrm{M})$ has been added to the stacking representation [16]. Thus, this leads to the notations N9R and M9R. We thus propose, in accordance with [16], to continue to differentiate between $\mathrm{N} 2 \mathrm{H}$ - and $\mathrm{M} 2 \mathrm{H}$-martensites.

Clearly, there exist more stacking sequences than those dealt with in ref [1]. McLarnan has applied in a set of papers [11] group theoretical techniques to the analysis of layered polytypic stacking and gives the mathematical tools for counting polytypes and for classifying them into space groups. This technique has been applied with success in determining the space groups of the diamond polytypes [12]. In his paper, McLarnan argues that the packing $(+1,+1,-1)$ (Hägg notation) for the $\mathrm{ABCBCACAB}$ stacking sequence should have layer-number 9 , not 3 , and that the sequence should be counted in the direction perpendicular to the basal plane. In table 4 of [11], which is partially reproduced in table 1 of [12], McLarnan gives the number of close-packings for any layer number $\mathrm{N}$ ranging from 1 to 50 and lists them according to the possible space groups. If it is noted that a three layer stacking within $R \overline{3} \mathrm{~m}$ is identical to the cubic close packing with space group $\mathrm{Fm} 3 \mathrm{~m}$, this is bringing the possible number of space groups to eight. This list shows that there are respectively $0,1,1,1,1,2,3,6,7$, and 16 possible sequences for a stacking of respectively $1,2,3,4,5,6,7,8,9$ and 10 close packed layers. Thus, there are 7 possible stacking sequences in the case of 9 layers, the stacking ABCBCACAB being one of them. A more detailed list of the stacking sequences and the associated symbols can be found in [18]. It is evident that, if the atom distribution in the basal plane is replaced by one corresponding to the $\mathrm{B} 2, \mathrm{DO}_{3}$ or $\mathrm{L}_{1}$ ordering, or if a deviation of the regular hexagon configuration in the basal plane occurs, the possible symmetry groups will be reduced. It must be emphasized that except for the case of $\alpha_{1,2}$-martensite and disordered martensites in general, the crystal symmetry can be provided by the phase symbols. Thus $\beta_{1,2}$-martensites and $\gamma_{1,2}$-martensites, whether normal $(N)$ or modified $(M)$, are respectively monoclinic and orthorhombic.

The next point of discussion concerns the unit cell. Conventional transmission electron microscopy has been and continues to be one of the most powerful tools to study martensites - their structure and microstructure -. A practising microscopist very often relies on certain recognisable features in the image or diffraction patterns to help him/her in identifying the type of martensite and any unusual feature in a known martensite. Moreover, a quick analysis of these features while operating the microscope enables one to manoeuvre ones way to the required crystal orientation. The features most often relied upon in this sense are the basal plane stacking shifts which are readily correlated with the existing nomenclature. This is not to say that it is impossible to do electron microscopy work using the correct structure and 
axes, as derived by the space group. But continuous streaks in a diffraction pattern related to the edge on faults certainly make a much easier reference for operating purposes and recognition in the microscope. It allows one also to easily recognise the difference between a normal and a modified martensite as nicely shown in [17]. This is one instance where a more easily recognisable symmetry in a pattern is preferred over true symmetry.

The last point for discussion is the monoclinic unit cell for the $\beta_{2}^{\prime}$-martensite with the $9 \mathrm{R}$ stacking sequence. As shown in fig.4(d) of ref [4] and in ref [13 \& 14], 3 layers are necessary and sufficient to describe the unit cell instead of the six as proposed in ref [1]. Thus, the monoclinic unit cell for the $\beta^{\prime} 1^{-}$ martensite - with the 18R stacking sequence- contains 6 layers as shown in fig.2 of ref [15]. In [15] it is quoted that "it is advisable to use the monoclinic cell that discloses the true symmetry of the $18 \mathrm{R}$ structure" (loc cit) in order to make conclusions concerning the types of antiphase boundaries.

From the foregoing discussions and arguments we conclude that

a) the phase symbols $\alpha^{\prime}$-, $\beta^{\prime}$ - and $\gamma^{\prime}$-, which are used to depict the martensites, provide much more information than structures alone and it is advisable not to abandon these $\alpha$-, $\beta^{\prime}$-and $\gamma^{\prime}$-martensite phase symbols.

b) the subscript or the absence of a subscript unambiguously designates the type of long range order or its absence and that its continued use is necessary.

c) in order to draw the attention to distortions induced by the ordering, the symbols $N$ (normal) or $M$ (modified) should be added to the stacking sequence symbol.

d) the use of the phase symbol alone satisfies the description of the stacking sequence so long as only one type of sequence has been reported to be observed. It is, of course, very instructive to give in a short-hand notation the exact type of stacking sequence, but then, according to [11], referred to the sequence as encountered along the direction perpendicular to the basal plane. Since the Zhdanov notation represents the stacking order rather than symmetry, the Zhdanov short-hand notation should be given -in this respect we agree with the condition, as expressed in [1], that the total period be measured along the perpendicular direction. Mentioning, moreover, the Ramsdel-notation may also be of use with reference to the 'earlier' publications or in case the reader does not have quick access to the ZhdanovRamsdell translation. The exact space group should be given, but mentioning the space group of the structure disregarding ordering and distortions may also be instructive.

e) in order to know how the MI8R- or M9R-martensite, respectively, is modified from the $N$ martensite, intensity distributions are best analysed in detail on the rows of diffraction spots lined up parallel to the $c^{*}$-axis. Therefore, indexing is best done according to the 18-or 9-layered unit cell, respectively, of the normal martensite.

f) the correct unit cell should be used to characterize the crystallographic features, such as Burgers vectors, anti-phase domain boundaries.

$g$ ) the current generally accepted and used nomenclature is adequate and should be retained.

Acknowledgements

L.D. would like to thank the Belgian National Science Foundation (FKFO-project) for support.

References

1. K.Otsuka, T.Ohba, M.Tokonami and C.M.Wayman, Scripta Metall. et Mater. 29, 1359 (1993).

2. Z.Nishiyama, "Martensitic Transformation", Academic Press (1978).

3. L.Delaey, K.Mukherjee and M.Chandrasekaran, Proc."International Summer Course on Martensitic Transformations -ICOMAT-82", ed Dept.Metall. \& Mat.Eng., KULeuven, p.7-1 (1982).

4. L.Delaey, M.Chandrasekaran, M.Andrade and J.Van Humbeeck, Proc.Int.Conf. "Solid-Solid Phase Transformations" (ed. H.I.Aaronson et al.), Pittsburgh, AIME, p.1429 (1982).

5. L.Delaey and M.Chandrasekaran, Scripta Metall. et Mater. 30, 1605 (1994) 
6. H.Warlimont and L.Delaey, Progress in Materials Science vol 10 (1974).

7. T.Saburi and S.Nenno, Proc.Int.Conf. "Solid-Solid Phase Transformations" (ed. H.I.Aaronson et al.), Pittsburgh, AIME, p.1455 (1982).

8. T.Saburi, S.Nenno and C.M.Wayman, Proc. Int. Conf. ICOMAT-79, MIT-Cambridge, USA p.619 (1979).

9. K.Otsuka and K.Shimizu, Proc.Int.Conf. "Solid-Solid Phase Transformations" (ed. H.I.Aaronson et al.), Pittsburgh, AIME, p.1267 (1982).

10. L.Delaey, T.Suzuki and J.Van Humbeeck Scripta Metall. 18, 899 (1984)

11. T.J.Larnan, Z. für Kristallogr., 155, 227, 246 and 269 (1981).

12. A.W.Phelps, W.Howard and D.K.Smith, J.Mater; Res. $\underline{8}, 2835$ (1993).

13. L.Delaey, J.Van Humbeeck, M.Chandrasekaran, J.Janssen, M.Andrade and N.Mwamba, Metals Forum, 4 , 164 (1981)

14. M.De Graef, L.Delaey and D.Broddin, phys.stat.sol. (a) 107,597 (1988).

15. M.Andrade and L.Delaey, Trans.Jap.Institute of Metals, 25, 778 (1984).

16. T.Tadaki, M.Tokoro and K.Shimizu, Trans. Jpn. Inst. Metals, 16, 285 (1975).

17. H.Kubo and K.Shimizu, Trans. Jpn. Inst. Metals, 17, 330 (1976).

18. B.I.Nikolin, 'Multilayer Structures and polytypism in Metallic alloys', Naukova Dumka, Kiev (1984)
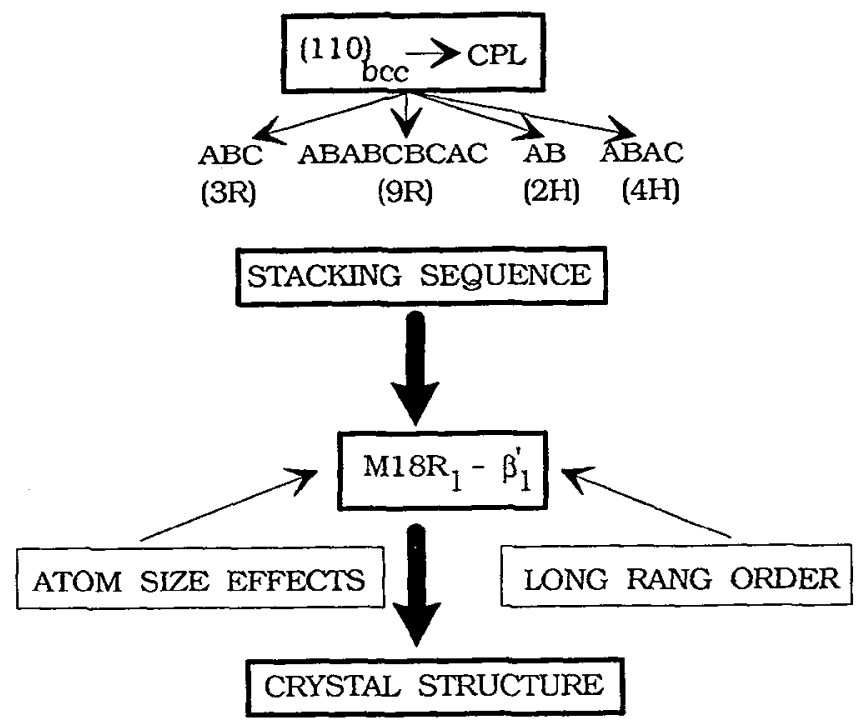

+ TWINS, STACKING FAULTS, MLXTURES

OF STACKING SEQUENCES

Figure 1: Development of crystal structure of martensite as determined by the parent phase ordering [3]. 
TABLE I

\begin{tabular}{|c|c|c|c|c|c|c|c|}
\hline Phase & Symbol & Stacking & Sequence & Crystal & Structure & & \\
\hline Matrix & Martensite & Ramsdell & Zhdanov & $\begin{array}{l}\text { Struktur } \\
\text { report }\end{array}$ & $\begin{array}{l}\text { Space group } \\
\mathbf{N}\end{array}$ & $\begin{array}{l}\text { Schoen } \\
\text {-flies }\end{array}$ & $\begin{array}{l}\text { crystal system } \\
\mathbf{N}\end{array}$ \\
\hline$\beta$ & $\begin{array}{l}\alpha^{\prime} \\
\beta^{\prime} \\
\gamma^{\prime} \\
\gamma^{\prime}\end{array}$ & $\begin{array}{l}3 \mathrm{R} \\
9 \mathrm{R} \\
2 \mathrm{H} \\
4 \mathrm{H}\end{array}$ & $\begin{array}{l}(1)_{3} \\
(21)_{3} \\
(11) \\
(22)\end{array}$ & $\begin{array}{l}\mathrm{A} 2 \\
\mathrm{~A} 1 \\
\mathrm{~A} 3\end{array}$ & $\begin{array}{l}\quad \operatorname{Im} 3 \mathrm{~m} \\
\mathrm{Fm} 3 \mathrm{~m} \\
\mathrm{R} 3 \mathrm{~m} \\
\mathrm{P} 6_{3} / \mathrm{mmc} \\
\mathrm{P} 6_{3} / \mathrm{mmc}\end{array}$ & $\mathrm{O}_{\mathrm{h}}{ }^{9}$ & $\begin{array}{l}\quad \text { cubic } \\
\text { cubic } \\
\text { trigonal } \\
\text { hexagonal } \\
\text { hexagonal }\end{array}$ \\
\hline$\beta_{1}$ & $\begin{array}{l}\alpha_{1}^{\prime} \\
\beta_{1}^{\prime}{ }_{1} \\
\beta_{1}^{\prime}{ }_{1} \\
\beta^{\prime \prime}{ }_{1} \\
\gamma_{1}^{\prime} \\
\gamma_{1}^{\prime}\end{array}$ & $\begin{array}{l}6 \mathrm{R} \\
7 \mathrm{R} \\
18 \mathrm{R}_{1} \\
18 \mathrm{R}_{2} \\
18 \mathrm{R}+2 \mathrm{H} \text { or } 3 \mathrm{R} \\
2 \mathrm{H} \text { (NorM) } \\
4 \mathrm{H}\end{array}$ & $\begin{array}{l}(1)_{6} \\
(6 I]_{2} \\
(21)_{6} \\
(1131)_{3} \\
(11) \\
(22)\end{array}$ & $\mathrm{DO}_{3}$ & $\begin{array}{l}\text { Fm3m } \\
\text { I2/m } \\
\mathrm{P} 2 / \mathrm{m} \\
\mathrm{I} 2 / \mathrm{m} \\
\mathrm{I} 2 / \mathrm{m}\end{array}$ & $\mathrm{O}_{h^{5}}$ & $\begin{array}{l}\text { cubic } \\
\text { monoclinic } \\
\text { monoclinic } \\
\text { monoclinic } \\
\text { monoclinic }\end{array}$ \\
\hline$\beta_{2}$ & $\begin{array}{l}\alpha_{2}^{\prime} \\
\alpha_{2}^{\prime} \\
\beta_{2}^{\prime} \\
\beta_{2}^{\prime} \\
\gamma_{2}^{\prime}\end{array}$ & $\begin{array}{lr}3 \mathrm{R} & \text { (M) } \\
3 \mathrm{R} & (\mathrm{N}) \\
9 \mathrm{R} & (\mathrm{M}) \\
9 \mathrm{R} & (\mathrm{N}) \\
2 \mathrm{H} \text { (NorM) } & \end{array}$ & $\begin{array}{l}(1)_{3} \\
(1)_{3} \\
(21)_{3} \\
(21)_{3} \\
(11)^{2}\end{array}$ & $\mathrm{B2}$ & $\begin{array}{l}\mathrm{Pm} 3 \mathrm{~m} \\
\mathrm{P} 2 / \mathrm{m} \\
\mathrm{P} 4 / \mathrm{mmm}^{\mathrm{P} 2 / \mathrm{m} 2 / \mathrm{m}} \\
\mathrm{Pmma}\end{array}$ & $\mathrm{O}_{\mathrm{h}}{ }^{1}$ & $\begin{array}{l}\text { cubic } \\
\text { monoclinic } \\
\text { tetragonal } \\
\text { monoclinic } \\
\text { monoclinic }\end{array}$ \\
\hline$\beta_{\mathbf{3}}$ & $\begin{array}{l}\alpha_{3}^{\prime} \\
\beta_{3}^{\prime} \\
\gamma_{3}^{\prime}\end{array}$ & $\begin{array}{l}6 \mathrm{R} \\
18 \mathrm{R} \\
2 \mathrm{H} \text { (NorM) }\end{array}$ & $\begin{array}{l}(1)_{6} \\
(21)_{6} \\
(11)\end{array}$ & $\mathrm{L}_{2}$ & $\begin{array}{l}\text { Fm3m } \\
I 2 / \mathrm{m} \\
\mathrm{I} 2 / \mathrm{m}\end{array}$ & $\mathrm{O}_{\mathrm{h}}{ }^{5}$ & $\begin{array}{l}\text { cubic } \\
\text { monoclinic } \\
\text { monoclinic } \\
\text { orthorhombic }\end{array}$ \\
\hline
\end{tabular}

